\title{
Land Cover Changes in Lower Jubba Somalia
}

\author{
Linda Ajuang Ogallo', Kenneth Mwangi², Philip Omondi², Gilbert Ouma1, Gordon Wayumba ${ }^{3}$ \\ ${ }^{1}$ Institute of Climate Change and Adaptation, University of Nairobi, Nairobi, Kenya \\ ${ }^{2}$ IGAD Climate Prediction and Application Centre, Nairobi, Kenya \\ ${ }^{3}$ The Technical University of Kenya, Nairobi, Kenya \\ Email: lindaogallo@gmail.com
}

How to cite this paper: Ogallo, L.A., Mwangi, K., Omondi, P., Ouma, G. and Wayumba, G. (2018) Land Cover Changes in Lower Jubba Somalia. American Journal of Climate Change, 7, 367-387.

https://doi.org/10.4236/ajcc.2018.73022

Received: March 7, 2018

Accepted: July 10, 2018

Published: July 13, 2018

Copyright $(9) 2018$ by authors and Scientific Research Publishing Inc. This work is licensed under the Creative Commons Attribution International License (CC BY 4.0).

http://creativecommons.org/licenses/by/4.0/

\begin{abstract}
Charcoal is the main cooking source of energy used by millions of households in Somalia and has been described as "black gold" because of the revenue it produces. The objective of this study was to understand the extent of land cover change, given the widely reported charcoal trade in the South of Somalia. Land cover change analysis was done using remotely data from Landsat imagery. Different images covering all districts in Lower Jubba from 1993/95, 2000 and 2014 were analysed and compared. A survey was conducted in Lower Jubba to determine the divers of deforestation and degradation in the region. Results showed a 50\% reduction in forest cover and a $17 \%$ reduction in woodlands between 1993/95 and 2014. Results from the survey showed charcoal production as a maladaptive response to climate extremes. If business continues as usual with deforestation, the entire area could completely be deforested in the future. Results from this study can be useful in the development of strategies for reforestation, environmental management and sustainable development for this region.
\end{abstract}

\section{Keywords}

Land Cover Change, Climate, Degradation, Deforestation, Charcoal Production, Sustainable Development, Somalia

\section{Introduction}

Over $80 \%$ of the urban population and $90 \%$ of rural populations rely on charcoal for in sub-Saharan Africa [1]-[6]. Globally, 10\% of the total anthropogenic net carbon dioxide $\left(\mathrm{CO}_{2}\right)$ emissions are from land use change [7]. The forest sector can have an impact on greenhouse gas emissions [8]. Charcoal, usually described as "black gold" because of the revenue it produces, is the main source of energy for cooking in Somalia [5] [9]. Somalia is largely a pastoralist country which re- 
lies on trees and shrubs for animal feed, and rivers to water animals particularly during the dry season [10] [11]. Deforestation and degradation could have a serious negative impact on an important natural resource that pastoralist communities depend on [12].

Charcoal harvesting is currently the largest driver of environmental degradation in south of Somalia [13] [14]. Though the use of charcoal for fuel is widespread across Somalia, it is the foreign demand that has been of great concern with an estimated 4.4 million trees logged annually for export [5]. It has been reported that charcoal production as a result of the war economy, has significantly depleted the country's natural resources [15]. Charcoal in Somalia had developed into one of the major export products, becoming a major source of income for $70 \%$ of poor and middle-income pastoralists in Somalia as minimal capital is required for production [16] [17] [18]. In some parts of Somalia, charcoal production is reported to have become mechanized and controlled by cartels [12].

According to the United Nation Environment Programme (UNEP) and the International Criminal Police Organization (INTERPOL), revenue from the charcoal trade in Africa is about USD 1.9 billion [19]. In Somalia alone, an estimated USD 340 - 360 million per year is made from illegal charcoal export [5] [19]. This is despite the 2012 UN ban on the export of charcoal from Somalia, citing the revenue from it a significant source for the militant group Al Shabaab [14].

Forest conservation also secures the livelihoods of communities that depend on them. More than 1.6 billion people depend on forests for food, water, fuel, medicines, traditional cultures and livelihoods [8]. Land degradation negatively impacts livelihoods and food security due to declining land productivity which increases poverty [12] [14]. Climate extremes and variability further threaten the livelihoods and food security for the already vulnerable community.

The impact for charcoal production in land cover change is not only a key threat to the natural vegetation but has been proposed to have a long-term impact on climate [3]. Forests also play an important role in emissions, sequestration, albedo and the hydrological cycle [20] [21] [22]. Evidence of tree cover changes in the south of Somalia so far has largely been obtained through satellite imagery with no verification of data due to high insecurity [15] [23] [24]. The objective of the study was to evaluate the changes in land cover in Lower Jubba Somalia as well as the drivers of deforestation and land degradation in this region.

\section{Data and Methodology}

\subsection{Data Used}

\subsubsection{Land Cover Change Data}

The monitoring of global environment changes is commonly done through the joint application of remotely sensed data acquired from various sensors. The inter-satellite cross-comparison among multiple sensors has become indispensable [25], especially in areas where there are no "ground truth" data. The strategy 
used in this study was to compare different images 1993/1995, 2000 and 2014. The images were extracted from Landsat 5, Landsat 7 and Landsat 8 and used for land cover classification.

Land use land cover (LULC) change analyses based on Landsat imagery data is commonly used in change detection studies. Landsat imagery has been extensively used for agricultural evaluation, forest management inventories among other applications [26]. Research has confirmed that many of their sensors are highly linearly related or vary slightly, which makes them useful for complementary data analysis [25]. Landsat provides the longest continuous record of satellite-based observations and is therefore invaluable in monitoring global land use change. Landsat also provides the only time series seasonal inventory of the global land surface [27].

Landsat 5 ( 1 - 5) carries the Thematic Mapper (TM) sensor and consists of seven spectral bands with a spatial resolution of 30 meters for Bands 1 to 5 and 7. Landsat 7 ( 1 - 7) carries the Enhanced Thematic Mapper Plus (ETM+) sensor and has a spatial resolution of $30 \mathrm{~m}$ for the six reflective bands, $60 \mathrm{~m}$ for the thermal band, and includes a panchromatic (pan) band with a $15 \mathrm{~m}$ resolution. Landsat 8 carries the Operational Land Imager (OLI) sensor and keeps the same settings as Landsat 7 but also adds new bands, such as coastal and aerosol studies, cirrus cloud detection and a quality assessment band, and adjusts the wavelength of each band [25].

GPS ground-truthing data was collected in the field in June 2016. Random points from field were collected and used for accuracy assessment of the classification. This was further supported with high resolution photography from SPOT 6. SPOT 6 has a resolution of 1.5 meter panchromatic and 6 meter multispectral (blue, green, red, and near-IR). Google earth imagery contains high resolution imagery that was also useful in corroborating the resulting classification.

\subsubsection{Primary Data}

Primary data was collected through surveys, focus group discussions, interviews and direct observation of the study area. The survey was conducted in Lower Jubba. Data for the survey was collected through one on one interview. Due to security concerns the survey was conducted by research assistants from the local university because of their access to the local community and their knowledge of the local language. The research assistants were trained on the survey tools. Cultural constraints also led to a larger number of men than women being interviewed. Two group discussions were held: one consisted of various community members and the other with local leaders. Key informant interviews were also conducted on one on one basis between January 2015 and October 2016. Some of the informants were interviewed once while others were interviewed multiple times depending on their knowledge of the subject matter to verify information.

\subsection{Methodology Adopted in the Study}

\subsubsection{Land Cover Change Detection}

Land cover refers to the physical characteristics of earth's surface, captured in 
the distribution of vegetation, water, soil and other physical features of the land, while land-use refers to the way in which land has been used by humans and their habitat [28]. Southern Somalia has diverse land cover ranging from grassland, shrubland, woodland, bare soil and forest.

The sample size shown in Figure 1 was selected for the land cover study as it covers all the three districts of lower Jubba. The analysis looks at Kismayo which is the most accessible area for ground verification and parts of Badhaadhe, Afmadow and Jamame, covering all districts in Lower Jubba as shown in Figure 1. The area was selected to provide a picture of the change in land cover as a result of charcoal production. The most standard technique for land cover change studies is to use a sampling strategy across the target area [3].

The Landsat Thematic Mapper (TM) (Landsat 5) and Enhanced Thematic Mapper Plus (ETM+) (Landsat 7) sensors acquire temperature data and store

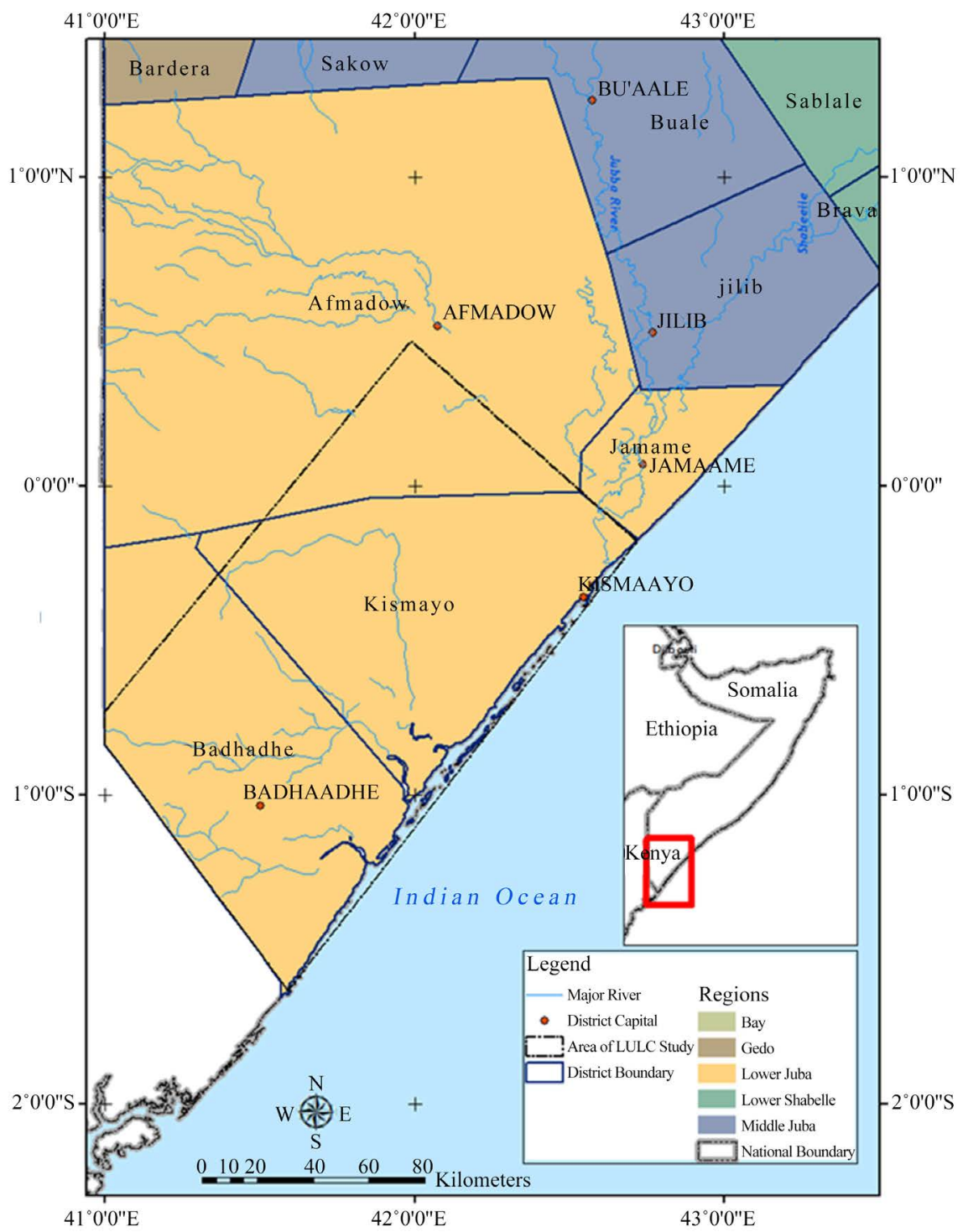

Figure 1. Study area. 
this information as an 8-bit digital number (DN) with a range between 0 and 255. Atmospheric correction is done through radiometric normalization and dark object saturation methods. Radiometric normalization is required to remove radiometric distortions and make the images comparable so as to correct surface directionality and atmosphere effects due to images acquired on different dates under different conditions [29] [30] [31].

A two-step process is used for the Landsat 5 and 7 images to convert the DNs to top-atmosphere reflectance (ToA) by first going through a spectral radiance conversion followed by a ToA reflectance conversion. Landsat 8 Operational Land Imagers stores information in reflectance rather than radiance as a 16-bit digital number (DN) data with a range from 0 and 65,536, thus requiring only a ToA reflectance conversion. The purpose of the conversions is to minimize any spectral differences in the images caused by acquisition time, sun elevation and sun earth distance by calibrating to a common radiometric scale. The Dark Object Subtraction (DOS) method was applied to all the images to cancel out the haze component caused by additive scattering from remote sensing data. The study area was then clipped from the images.

The Red band $(\mathrm{R})$ in the Landsat images discriminates vegetation, the Green band (G) emphasizes peak vegetation, which is useful for assessing plant vigor; the Blue band (B) which shows bathymetric mapping, distinguishing soil from vegetation and deciduous from coniferous vegetation; the near Infrared band (NIR) which emphasizes biomass content and shorelines; the short wave infrared 1 (SWIR-1) which discriminates moisture content of soil and vegetation; penetrates thin clouds; and the short wave infrared 2 (SWIR-2) band which improves moisture content of soil and vegetation and thin cloud penetration. A layer stack was created from these bands.

Given that the region of interest is along the coast line most of the images had high cloud cover, thus images with low cloud cover were difficult to obtain. This led to the Mosaicking of the 1993 and 1995 Landsat Images. This challenge was then further overcome by the development of a cloud and shadow mask that comprises of the cloud area and shadow area obtained from a supervised classification. The mask was created for each year 1993/5, 2000 and 2014.

Through a raster operation, the masks created were added up to develop a common cloud and shadow mask, with cloud and shadow areas with a given value of 0 . This was to enable one-to-one change comparison in the cloud free images and avoid inaccurate land cover changes e.g. clouds to woodland.

Image classification was done using supervised classification which applies maximum likelihood algorithm through ERDAS. This method assumes the probability that a pixel belongs to a particular class and the probabilities are equal for all classes and that the input bands have normal distributions. A quantitative analysis of the different classes was then done using a change matrix so as to observe a visual output of the change in the classes over the years. Unfortunately the method tends to over-classify signatures with relatively large values 
in the covariance matrix, pixels that should be unclassified become classified, and class variability is not considered. The cloud mask demonstrated improvement in the accuracy of the analysis of the images used in the study and avoided inaccuracies like those that would for example present clouds as woodland.

Land cover change analysis was done for the images of 1993/95, 2000 and 2014 in the Erdas Imagine change matrix tool. The change matrix results were analyzed in ArcGIS for identification of change areas. The resulting classification was therefore verified manually using high resolution imagery and ground verification. Google earth also proved useful in the verification of data. In between classes, there were confusions which required manual manipulations that may have resulted in errors. Examples include: close similarities between grassland and shrubland, scarce woodland and dense shrubland, small scale farms and shrubs.

Accuracy assessment of land cover classification is important to figure the degree of "correctness" of a classification [32] [33]. The accuracy in this study was conducted by applying both ground data collected from the field and high resolution imagery to the 2014 classified image. Accuracy assessment is done on the 2014 image because the reference images used are closer in the date of acquisition to the 2014 image than images from 2000 or 1993 and therefore more comparable. High resolution imagery was largely used due to inaccessibility in some areas of Lower Jubba due to insecurity.

Mapping accuracy was done using the confusion matrix and Kappa Khat methods for the 2014 image [32] [34]. Kappa Khat method is a measure of agreement between predefined producer ratings and user assigned ratings, calculated by the formula:

$$
K=P(A)-P(E) / 1-P(E)
$$

where $P(A)$ is the number of times the $\mathrm{K}$ agrees, and $P(E)$ is the number of times the $\mathrm{K}$ are expected to agree only by chance [34]. The number of points used in the confusion matrix was 76 points using field points and high resolution imagery. The overall accuracy of the classification was determined. The overall accuracy is the proportion of the total number of predictions that were correct. It is calculated by dividing the total number of correctly classified pixels by the total number of reference pixels.

The producer accuracy shows how well a certain area can be classified (omission error) this is the fraction of correctly classified pixels with regard to all pixels of that ground truth class. It is calculated by dividing the number of correctly classified pixels in each category by the total number of reference pixels "known" to be of that category. The user accuracy shows the probability that a pixel class on the map correlates with the category on the ground (commission error). The user accuracy is the fraction of correctly classified pixels with regard to all pixels classified as this class in the classified image. It is computed by dividing the number of correctly classified pixels in each category by the total number of pixels that were classified in that category [32]. 
Post processing of the classified image was compared using cross-tabulation in order to determine qualitative and quantitative aspects of the changes for the periods from 1993/95 to 2014 in ArcGIS 10.2.

\subsubsection{Analysis of Primary Data}

Primary data was used to determine the impacts of climate and variability on the livelihoods of the community and the significance of charcoal production. The primary data was also aimed at collecting information to meet the first and second objective.

1) Sample size

Sampling is a way of selecting a number of individuals for a study to represent the larger group from which they were selected. The size of the sample population was determined using a sample size calculator in the Creative Research Systems survey software [35]. The software uses the confidence interval, confidence level and population size to determine the sample size.

The confidence interval is the margin of error, while the confidence level shows the probability that the value of a parameter falls within the confidence interval. The confidence level selected was $95 \%$. This gave a sample size of one hundred and fifty for the estimated 183,000 people in the sample area. Probability sampling, also known as random sampling was used to select the one hundred and fifty participants for the survey, whereby every sample has an equal chance of being selected.

\section{2) Survey}

Permission was sought from the regional government to conduct the survey. Questionnaires were used to collect data from the population in Kismayo. The survey was conducted in the port town of Kismayo, in Lower Jubba. The advantage of carrying out the survey in Kismayo was that it is a melting pot of clans from all over Jubbaland and would therefore allow for collection of information that would create a complete picture of the region. There have been no population surveys carried out in Somalia since the collapse of the government in 1991 and the population is not known. The target population in Kismayo as estimated by African Union Mission in Somalia (AMISOM) is 183,000 [36]. The United Nations Population Fund (UNFPA) estimates the population in Kismayo to be 172,861 [37].

The questionnaire was designed to collect bio-data in addition to understanding the state of the environment as well as understanding the behavior and attitudes of the population towards charcoal production. The survey was translated to the local dialect, and five local students trained on how to conduct the survey. No incentives were offered to the participants in the survey. Participants from the survey were selected at random to participate in a focus group discussion, due to cultural restrictions, all participants who attended the discussions were male.

The data once collected was scored, analyzed and edited. Descriptive analysis was used to analyses the primary data which was then presented in tables, charts 
and graphs. Multiple univariate and multivariate analyses were also done.

3) Key Informant Interviews

Key informant interviews are in depth interviews of people selected for their first-hand knowledge about a topic of interest [38]. Interviews were conducted with key informants from the community to design the research, to understand and identify history of land use in the area of interest. The key informants were important in understanding the existing policies and any past and future planning on land use. The interviews also helped expand on the motives, views and attitudes of the respondents from the survey. The informants were from international and regional organizations working in the South of Somalia, local NGOs, representatives from the Federal Government of Somalia, and representatives from the Jubbaland administration and persons from Lower Jubba region with knowledge on the area. The methodology used for the interviews was both structured and unstructured. An interview guide was created to ensure all aspects of information required were included but the interviews ware unstructured. Some key informants were interviewed multiple times over a long period of time while others were interviewed once based on the scope of their knowledge and their willingness to engage in the research.

\section{Results and Discussion}

\subsection{Classification Results}

The initial classification resulted into 36 signatures. These were checked for accuracy and assigned new classes for generation of 6 classes as summarized in Table 1 below.

The spatial distribution of land cover is shown in Figures 2(a)-(c). Some of the changes in the vegetation can be seen in the progression from the 1993-95 image, to 2000 image and 2014 image. A decrease in vegetation and increase in bare-land from 1993-95 to 2014 is evident in Figure 2. These results support reports of change in the distribution of grasslands and shrublands, savannas and woodlands, and forests in Africa [39].

\subsection{Accuracy Assessment}

The results of the accuracy assessment showed an overall accuracy of $88.16 \%$ with a Kappa coefficient of 0.84 . This means that $88 \%$ of the image classification matched the reference data. The general target for an accuracy assessment is $85 \%$ [33], the overall accuracy for the study exceeds this target and the results therefore represent a strong agreement. Table 2 shows the producer and user accuracy for each class.

A user accuracy of $90 \%$ was reported for the forests, this is probably because the forested areas are well known and easily classified. The woodlands reported a user accuracy of $80 \%$ while $71 \%$ was reported for the shrublands. Bare land/artificial had the highest accuracy of $97 \%$ probably because the residential areas classified under this classification are close together and easy to spot. The 
use of remote sensing and GIS to determine the change in land-use and land cover has been used as a satisfactory method [40] [41] [42].

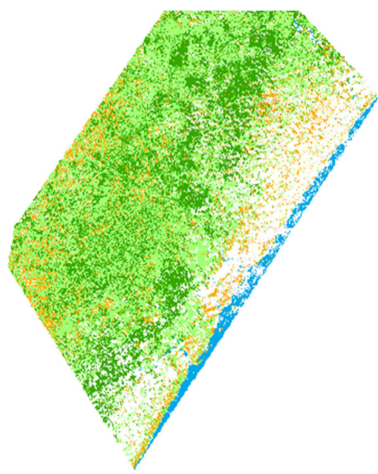

Land Cover 1995

(a)

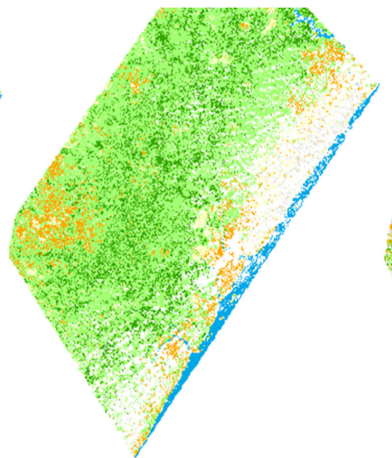

Land Cover 2000

(b)

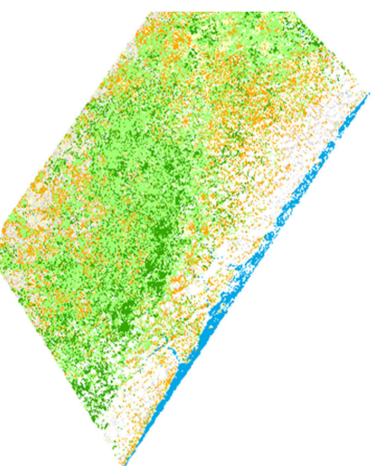

Land Cover 2014

(c)

Figure 2. Classified images of the land cover in the study area for 1993/95(a), 2000(b), 2014(c).

Table 1. Land Cover Classes.

\begin{tabular}{ll}
\hline Class Name & Land Cover Types \\
\hline 1) Forest & Dense trees mainly in hilly areas and along the rivers \\
2) Woodland & Acacia and other woodlot in less dense formation \\
3) Shrub land & Areas with shrub vegetation interspersed with grass \\
4) Grassland & Savannah grassland \\
5) Bare/Rock/Urban & Rocky river bed, rocks, bare soils and Urban Areas \\
6) Water & Open water in rivers and the Indian Ocean \\
\hline
\end{tabular}

Table 2. Accuracy assessment tabulation.

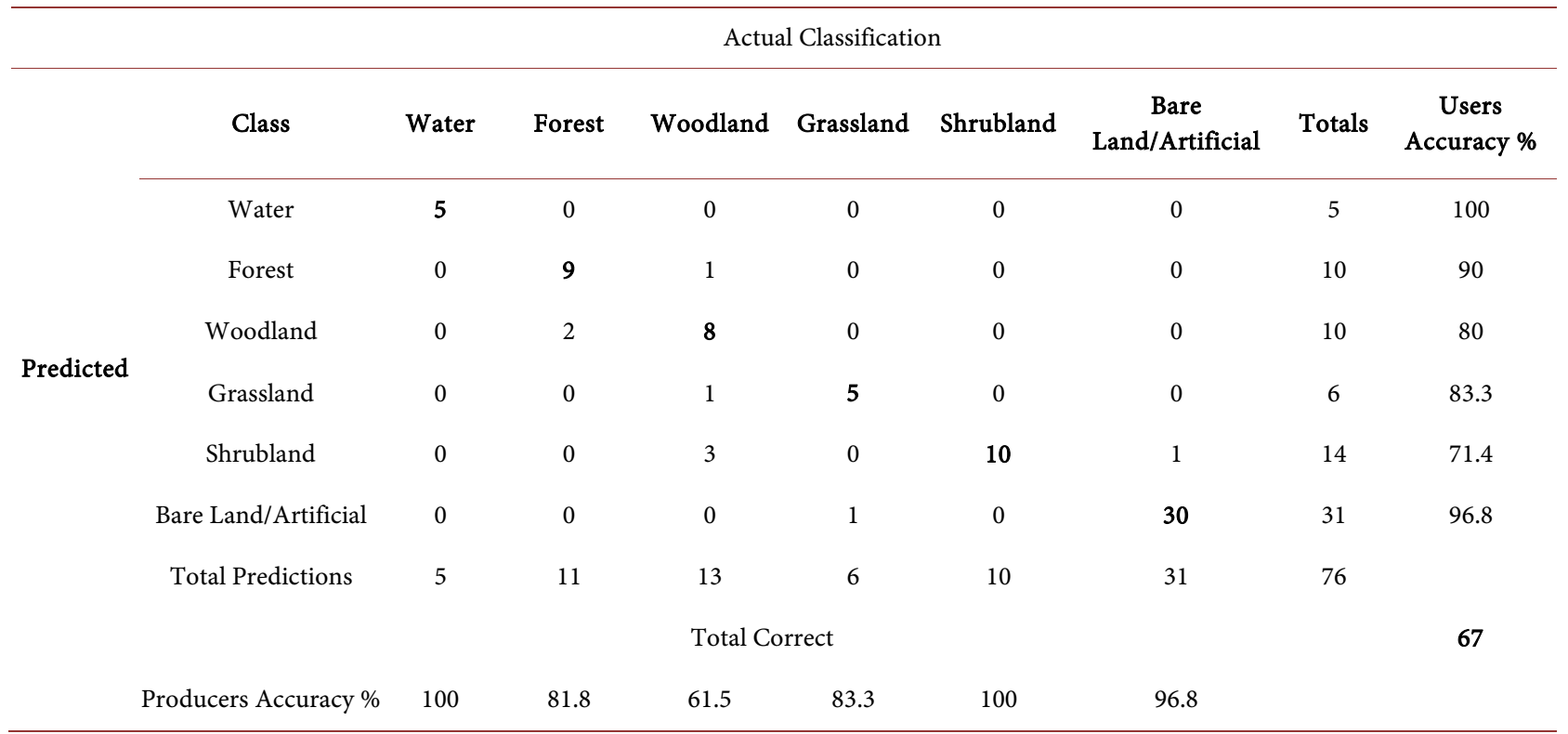




\subsection{Land Cover Change Results}

The land cover changes were analysed and categorized based on loss or gain in vegetation as summarized in Table 3 below.

Figures 3(a)-(c) maps out the land cover changes in Lower Jubba. Results seen in Figure 3(a) show that the most significant change between 1993-95 to 2000 was degradation from forests and woodland. This type of degradation shows a threat to the natural vegetation and has implications on carbon stocks. The degradation seen is supported by reports of pastoralists turning to charcoal trade after the ban on export of livestock due to Rift Valley Fever (RVF) that hit Somalia in 1998/1999 [32]. The Rift Valley Fever outbreak is also linked to excessive flooding reported in Somalia around the same period, [43] and coincides with the enhanced rainfall anomalies in 1997-98 [44].

The most significant change seen in Figure 3(b) and Figure 3(c) is deforestation. In this study deforestation was categorized as the change from forests or woodlands to grassland, bare land or shrubs. Results in Figure 3(b) show significant deforestation from 2000 to 2014. During this period, there were also reports

Table 3. Summary of land cover change categorization.

\begin{tabular}{|c|c|}
\hline Change Type & Cover category \\
\hline Deforestation & Forest, Woodland to Shrubs, Grassland and Bare \\
\hline Degradation & Forest to Woodland \\
\hline No Change & Constant cover type \\
\hline Reforestation & $\begin{array}{c}\text { Woodland to Forest; Grassland, Shrub or Bare to } \\
\text { Woodland/Forest }\end{array}$ \\
\hline Other Change & Other changes \\
\hline
\end{tabular}

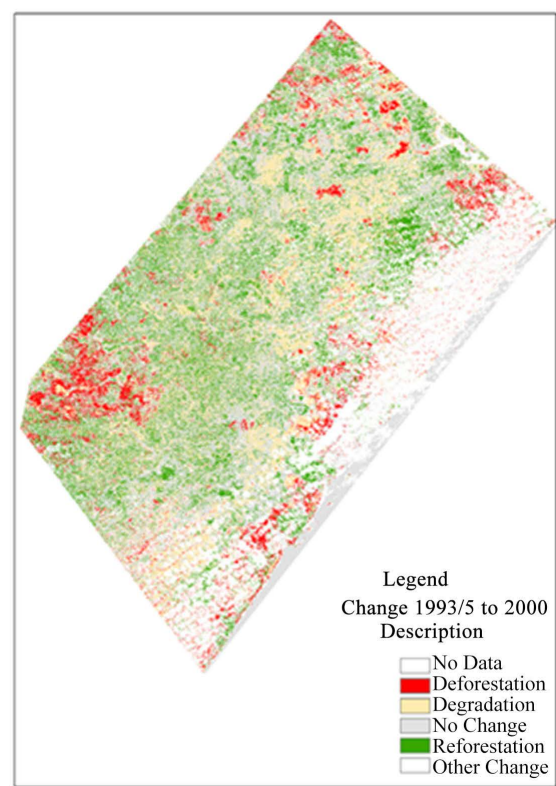

(a)

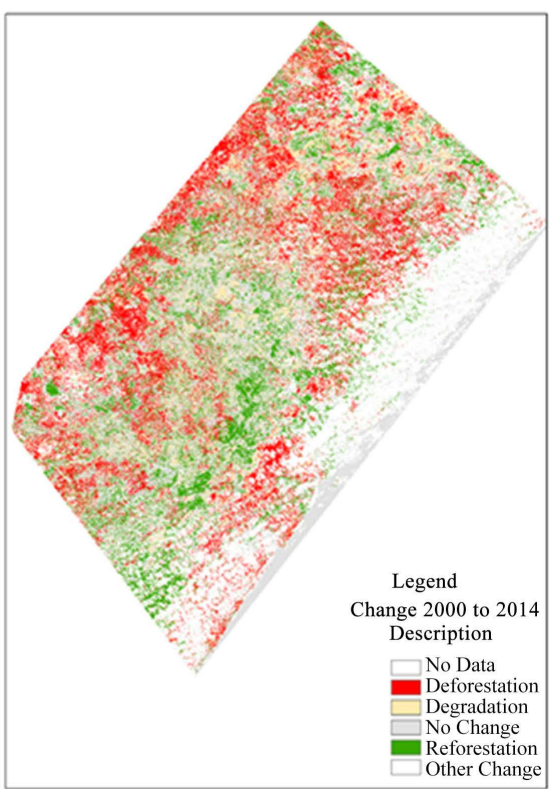

(b)

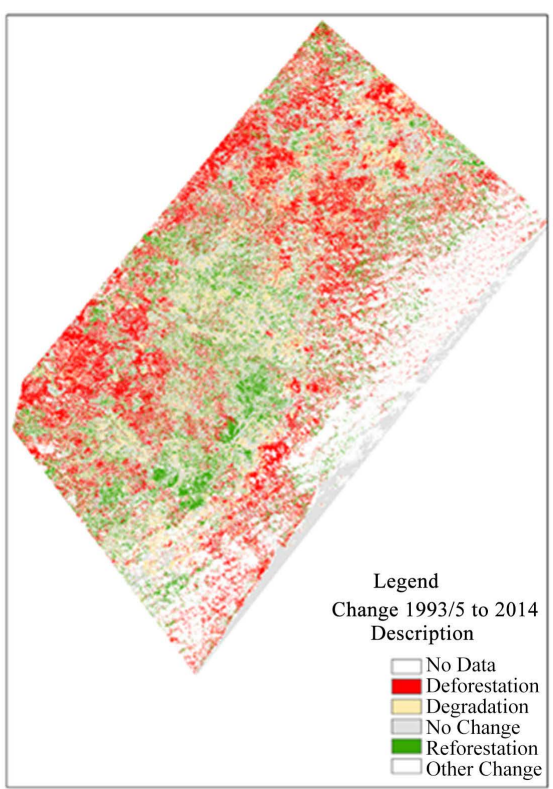

(c)

Figure 3. Change in land cover map 1993 to 2014. 
of a Rift Valley Fever outbreak in 2000-2002 and 2006-2007 that also lead to a ban in the export of livestock from Somalia [45].

The deforestation seen in this study is supported by reports of pastoralists coping to loss of livelihood by cutting trees for charcoal production [18]. Figure 3(c) shows significant deforestation between 1993-95 to 2014.

Re-sprouting of forests after injury, such as slash and burn inflicted by charcoal production, is a shortcut for forest recovery [46]. Natural re-sprouting and re-growth of wood biomass is an important source of regeneration of deforested and degraded areas. Climatic change-induced water stress has however been found to threaten the viability of trees by suppressing their regeneration [47].

In fact several studies have shown the risk posed by drought to forests [46] [47] [48]. The extended periods of below normal rainfall [44] show climate variability could be preventing the re-growth of natural vegetation, resulting in the overall magnitude deforestation and degradation seen in Figure 3(c).

Figure 4 highlights specific areas of forest conversion to woodland and to bare land. From the images an area that has a dense population of trees taken in $1993 / 95$ becomes sparsely populated with trees in 2000, and becomes shrubland and grass land, verifying the deforestation. SWALIM identified the dark spots shown in the images in Figure 4 as charcoal production sites [5]. The images show several charcoal production sites in the area that is classified as having experienced deforestation.

The region of study experienced about $50 \%$ reduction in forest cover between 1993_95 and 2014, and 16\% reduction of woodland in the same time period as shown in Table 4 . The reduction of tree and forest cover is further evidenced by the increase in bare-land and grassland by over 300\% each. There was an increase in woodland between 1993/5 and 2000 showing that some of the areas that had forest cover had been converted into woodlands, and can be seen in Figure 5.

Results from the analysis on the change in land cover are seen in Table 4 below.

Reports on Sub-Saharan Africa give a 16\% decrease in total forest cover and $5 \%$ decrease in total non-forest cover [7]. Results from this study show that the rate of deforestations in Lower Jubba is much higher. Natural regeneration of deforested areas would have been influenced by the recurrence of below normal anomalies between the year 1993 and 2014 [44]. Aside from impacting the natural regeneration of vegetation, the droughts reported for Somalia in 1999, 2008-09 and 2010/11 [43] also has an impact on availability on water and pasture impacting on livelihoods. The impact of climate variability is driving pastoralists to charcoal production thus increasing land degradation.

If deforestation and degradation continue at the same rates shown in Table 4, Lower Jubba could experience complete deforestation in the future, particularly if no mitigation measures are taken. Complete deforestation would create significant livelihood challenges for pastoralists in this region. Deforestation could increase the risk and spread of disease by increasing artificial water pools that can become breeding sites for malaria-carrying mosquitoes. It could also possibly 
extend tsetse zones which would negatively impact livestock in the region. Camel trypanosomiasis caused by tsetse flies is the most prominent single cause of economic losses in camel rearing areas, causing morbidity of up to $30.0 \%$ and mortality of around 3.0\% [49].

Table 4. Land cover in area of interest in 1993/95, 2000 and 2014.

\begin{tabular}{|c|c|c|c|c|c|c|}
\hline \multirow[b]{2}{*}{ Class } & \multicolumn{2}{|c|}{ Area in $\mathrm{Ha}$} & \multicolumn{4}{|c|}{$\%$ change } \\
\hline & $93 \_5$ & 2000 & 2014 & $2000-93 / 5$ & $2014-2000$ & $2014-93 / 5$ \\
\hline Water & $57,172.5$ & $61,212.15$ & $58,458.06$ & $7 \%$ & $-5 \%$ & $2 \%$ \\
\hline Forest & $520,163.7$ & $288,206.5$ & 259,764 & $-45 \%$ & $-5 \%$ & $-50 \%$ \\
\hline Woodland & 786,299 & $1,015,097$ & $655,032.1$ & $29 \%$ & $-46 \%$ & $-17 \%$ \\
\hline Grassland & $49,258.71$ & $137,856.1$ & $198,129.3$ & $180 \%$ & $122 \%$ & $302 \%$ \\
\hline Shrubland & $200,753.6$ & $131,611.1$ & $293,250.7$ & $-34 \%$ & $81 \%$ & $46 \%$ \\
\hline $\begin{array}{c}\text { Bare } \\
\text { Land/Artificial }\end{array}$ & $47,270.43$ & $26,935.56$ & $196,283.9$ & $-43 \%$ & $358 \%$ & $315 \%$ \\
\hline Total Predictions & $57,172.5$ & $61,212.15$ & $58,458.06$ & $7 \%$ & $-5 \%$ & $2 \%$ \\
\hline $\begin{array}{c}\text { Producers } \\
\text { Accuracy \% }\end{array}$ & $520,163.7$ & $288,206.5$ & 259,764 & $-45 \%$ & $-5 \%$ & $-50 \%$ \\
\hline
\end{tabular}

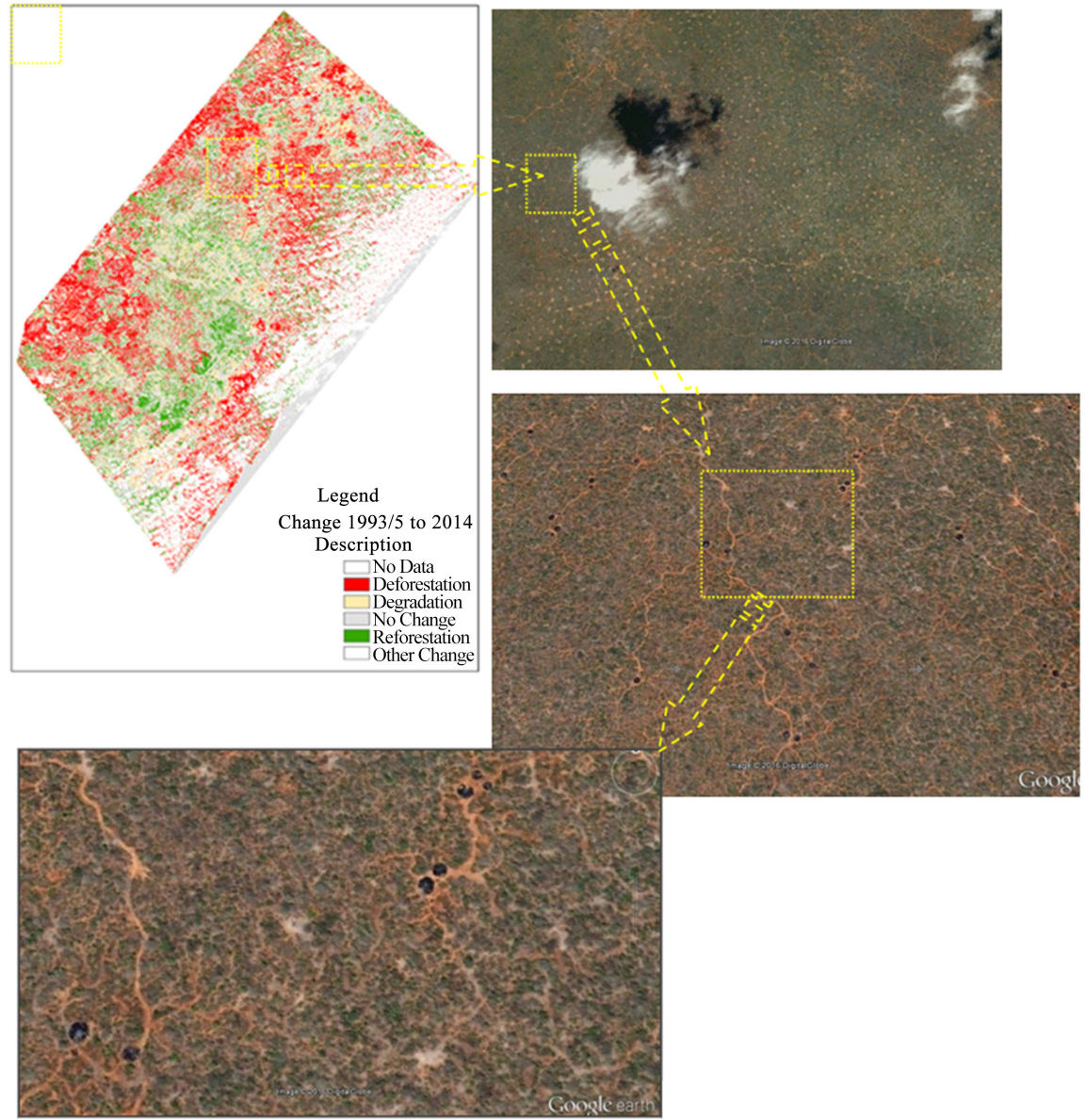

Figure 4. Forest conversion to woodland (degradation) then to bare land (deforestation). 


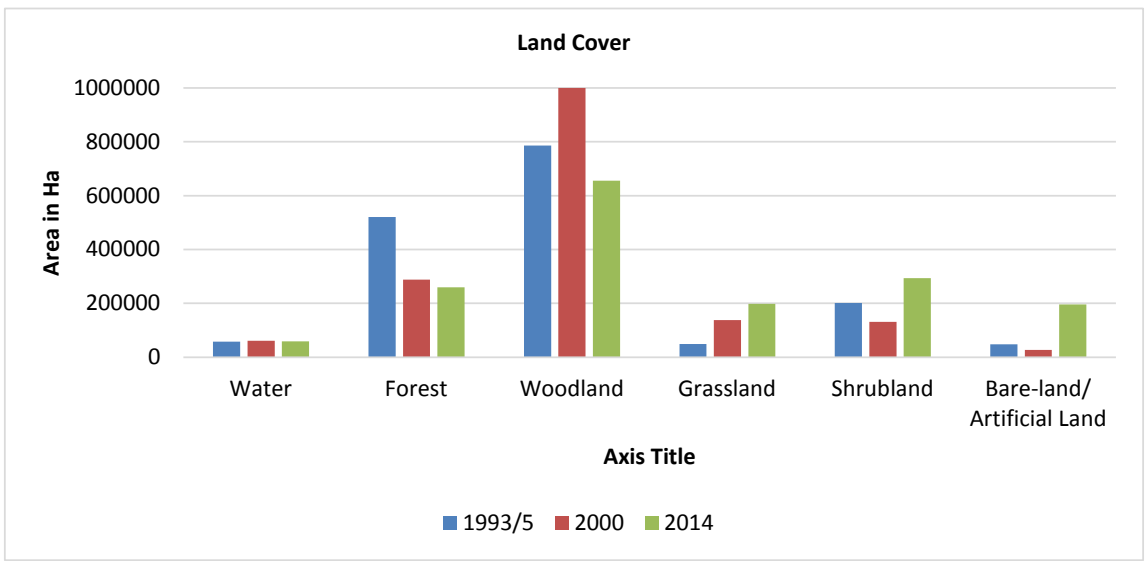

Figure 5. Land Cover between 1993/5 and 2014.

\subsection{Land Use Drivers}

Results from the survey showed that the main driver of changes in land cover in Lower Jubba is charcoal production (Figure 6). The expansion of agriculture and urbanization are drivers as well. This is supported by studies that have attributed deforestation to charcoal production in Sub-Saharan Africa [3] [5] [6]. It is further supported by literature that lists population growth and economic factors as drivers of land cover change [50].

Of the respondents that admitted to participating in charcoal production for export, $29 \%$ of these were pastoralists, $14 \%$ crop farmers and $28 \%$ listed their occupation as other than agriculture or charcoal production (Figure 7). This is supported by several studies that have stated that pastoralists in Somalia participated in the trade of charcoal as a result of the loss of livestock due to climate variability, and the ban in the export of livestock that occurred between 1998 and 2008 due to Rift Valley Fever (RVF) epidemics [51].

The results are also similar to studies on pastoralists in Somaliland, Malawi, Tanzania, southern Ethiopia, who turn to charcoal production as an alternative means of livelihood particularly when faced with climate extremes [52] [53] [54] [55]. Results further show that the export of charcoal is as a result of a livelihood challenge affecting not just the pastoralists but the entire community as well. Adverse impact of climate variability on livelihoods is high with $73 \%$ of the respondents having a significant decrease in household income as a result of bad weather conditions. Frequent and prolonged drought in this region is increasing the community's vulnerability reducing their ability to further adapt to climate shocks.

Poverty has played a role in the engagement of the local community in charcoal production. Key informants stated that the income received by majority of the local community in Lower Jubba from the charcoal trade is not much. This is supported by several studies on the trade of charcoal in other parts of Africa that state the same [53] [54] [55] [56]. Charcoal production is not a means to get rich for the local community but to put food on the table and to afford to send their 


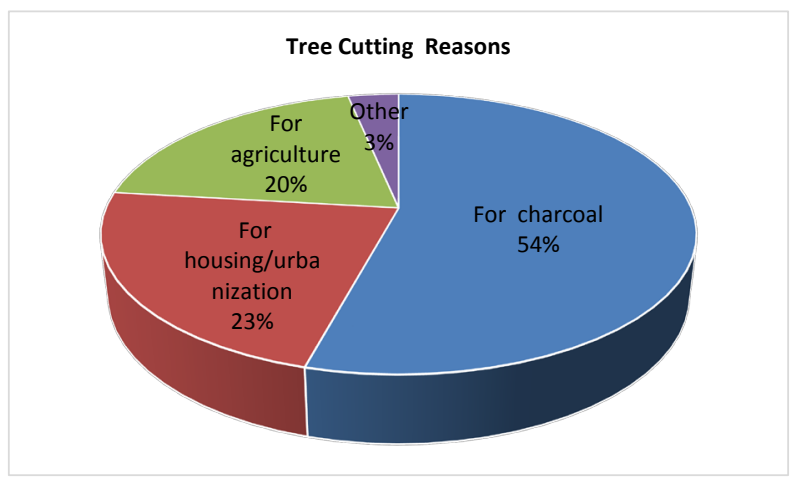

Figure 6. Reasons for tree cutting in Lower Jubba.

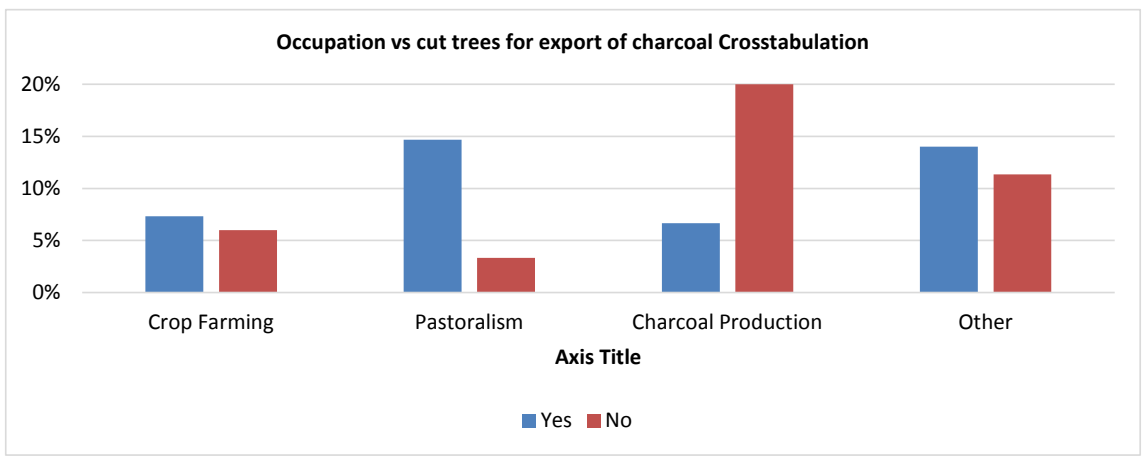

Figure 7. Occupation of respondents participating in the export of charcoal.

children to school. The charcoal production business in Lower Jubba is however said to be growing in popularity and involving not only the impoverished people. Continued news reports of it being a multi-million dollar industry has led to diverse populations getting into the trade with some areas reported to have highly mechanized systems for harvesting and producing the charcoal.

\subsection{Community Behaviors and Attitudes}

Charcoal production is a widely accepted practice among the local community, though many understand it is a topic of taboo not to be discussed with the international community. $90 \%$ of the respondents in the survey admitted that they cut trees for household fuel consumption while $69 \%$ stated that they cut trees for charcoal export as seen in Figure 8. Some of the community members view the ban on the export of charcoal as an imposition by the international community. Majority of the local community does not understand the risks posed by the practice. Key informants further stated that charcoal from Somalia in the past has been shipped under falsified documents to by-pass the international ban. Due to high international scrutiny, the newly formed local administration also placed a ban on the export of charcoal in June 2013.

The charcoal production problem is complex and is one that was done with no regulation for over two decades. A recurrence of depressed rainfall published by Ogallo [44] means the natural regeneration to assist in the recovery of dis- 
turbed vegetation is not occurring as fast as the deforestation and degradation. Charcoal production in this community is tied to economic development. The struggle for many seems to be out of necessity and not apathy. $40 \%$ of the respondents agreed that development and environmental protection should go hand in hand, though $18 \%$ believe that the government should prioritize development above all else. $44 \%$ believe that cutting trees is alright if it brings economic benefit while $66 \%$ believe that selling charcoal is an important means of supporting the economy as seen in Figure 9. Despite a large number of the respondents stating charcoal production as an important means of livelihood, when asked if they would play an active role in stopping the production of charcoal, $66 \%$ of the respondents stated that they would.

People from all occupations participate in charcoal production as a means to supplement their income as seen in Figure 10. It is important to note that a large number of respondents that identified their occupation as in charcoal production stated that the charcoal they produce was not for export but for local consumption. $85 \%$ of pastoralists admitted to cutting trees for charcoal export while 88\% stated that they do it for local sale as shown in Figure 10(a) and Figure 10(b). Liberation of Lower Jubba has driven militia into hiding in the forests which has restricted access to the forest. This is supported by respondents who stated minimal access to the forest as seen in Figure 11. The forests are as a result being protected by the militia who now need it to provide security cover.

The survey shows that in Lower Jubba charcoal is the primary source of energy. The Federal Government reports that $98 \%$ of the urban households in Somaliause traditional inefficient charcoal stoves, and most of the rural and nomadic population use firewood and inefficient biomass stoves [57]. Various reports also support the results of the study showing the export of charcoal from the South of Somalia as a major livelihood source [5] [9] [15] [58]. 90\% of the respondents agreed that charcoal burning is one of the primary reasons for tree cutting in Lower Jubba. The Federal Government of Somalia has further stated a need to

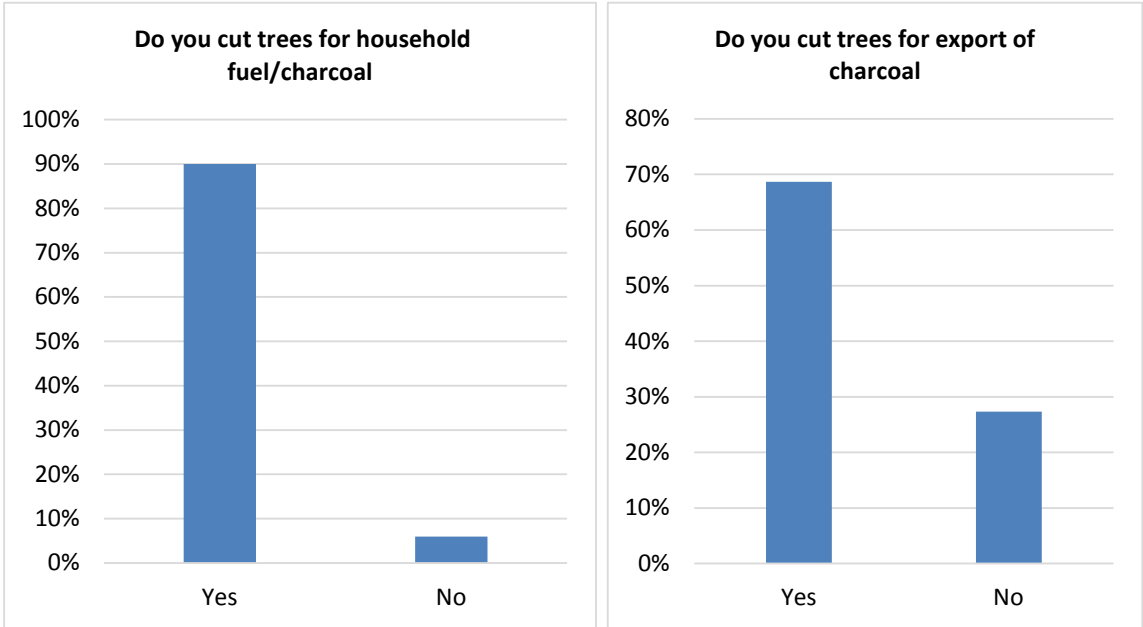

Figure 8. Respondent's participation in tree cutting activities. 


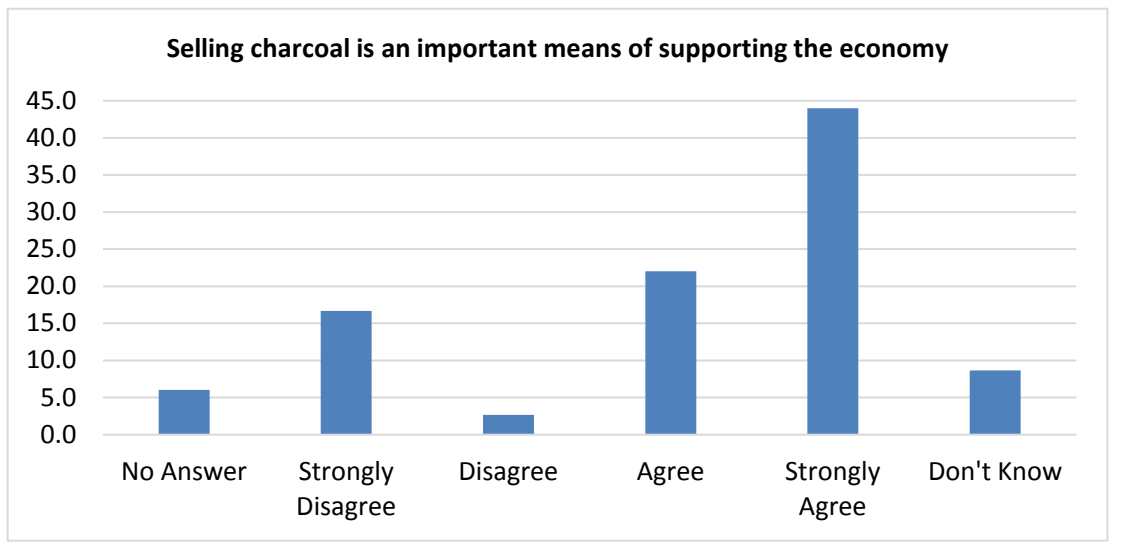

Figure 9. Respondents' attitudes towards contribution of charcoal burning to the economy.

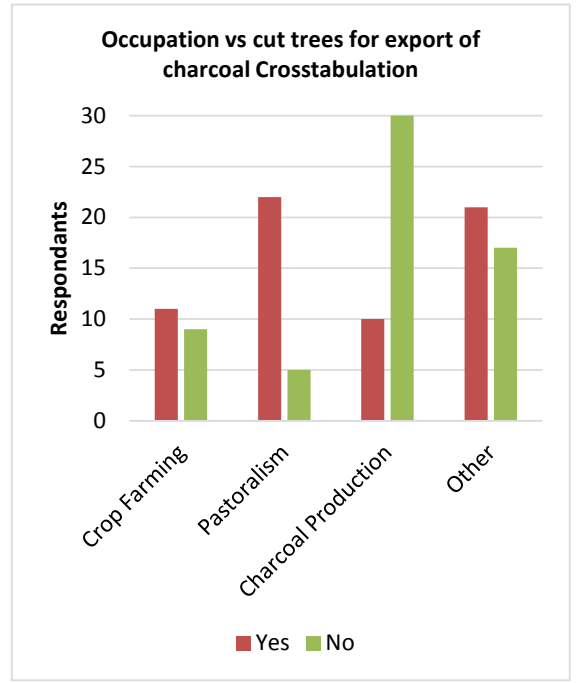

(a)

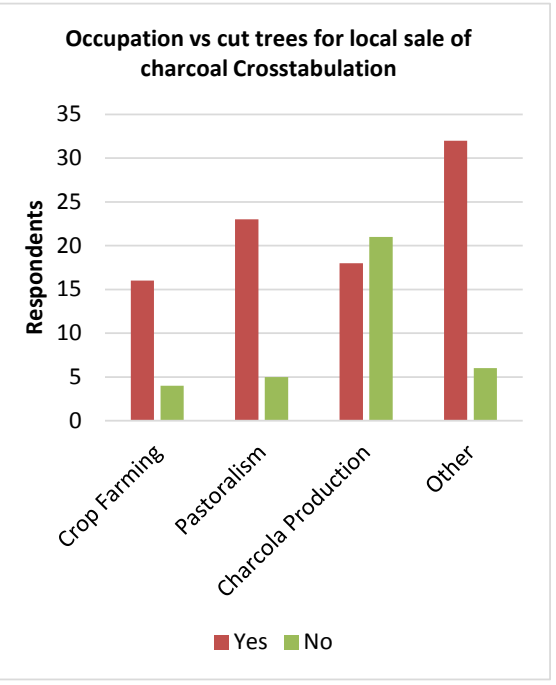

(b)

Figure 10. Participant's occupation compared with their participation of tree cutting for charcoal production.

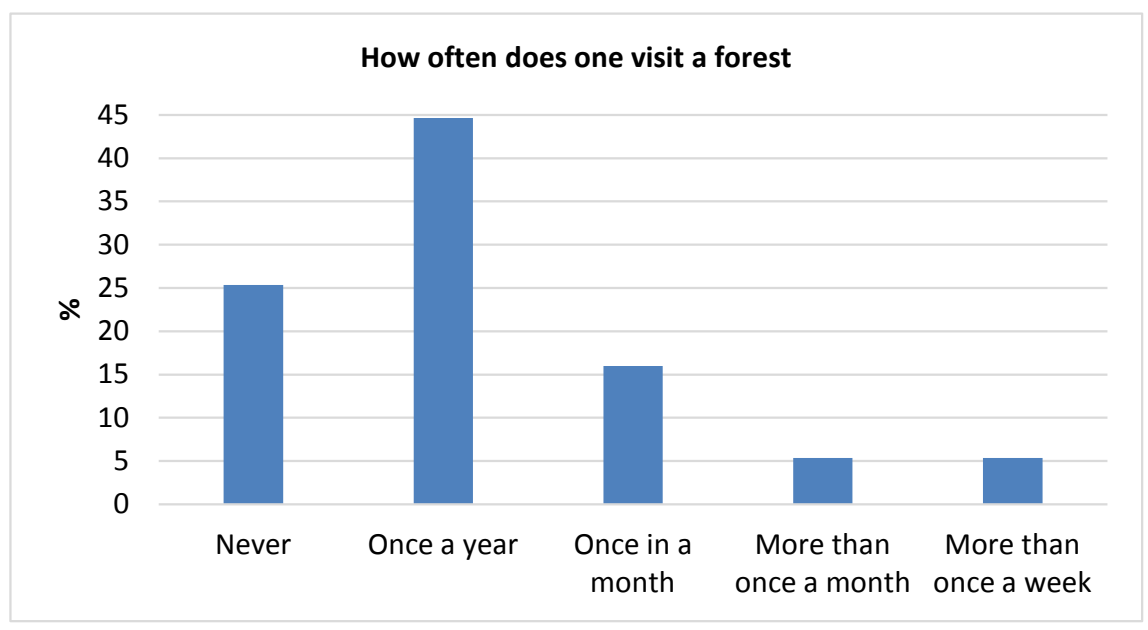

Figure 11. Graph showing how often respondents visit a forest. 
ensure the sustainability of household fuels supply by reducing pressure on the biomass resources (vegetative cover) of Somalia and through substitution of modern fuels, kerosene and liquefied petroleum gas (LPG) for biomass fuels [57]. This had not been implemented in Lower Jubba during the period of study.

\section{Conclusions}

The objective of the paper focused on evaluating the changes in land cover in Lower Jubba for possible impacts of human activity. The results from the study revealed that Lower Jubba has experienced significant deforestation of up to 50\% reduction in forest cover between 1993 and 2014. The region has further experienced significant degradation in the same period with up to $17 \%$ reduction in woodlands. The classification of woodlands reported a user accuracy of $80 \%$. Bare land/artificial land increased to $315 \%$, which could also be associated to an increase in settlement. An increase in grassland and shrubland was seen as well.

It may be concluded from the results that main reason for the rapid deforestation and degradation in Lower Jubba was primarily due to charcoal production. The expansion of agriculture and urbanization were highlighted as well. It was also evident from the study that loss of livelihoods due to climate extremes increases the poverty for communities in Lower Jubba. The local communities attempt to cope with the impacts of climate extremes including prolonged drought and floods by turning to the charcoal trade.

The study concluded that if business continues as usual with charcoal trade and other deforestation activities, Lower Jubba could have complete deforestation in the future. As the region stabilizes, the growth of the population is expected, particularly with repatriation of refugees back to their homes. Population growth means an increase in demand for charcoal, which is currently the main source of energy. This would increase the rate of degradation even further if effective measures are not taken to counter it. The natural process of regeneration of vegetation that would have naturally reduced the overall degradation has been hindered by climate extremes associated with climate variability and change.

Sustainability in reforestation and tree farming could address the need for charcoal while simultaneously engaging in soil and water protection, as well as investing and enhancing the use of clean renewable energy resources such as hydropower, solar and wind. Reforestation and Forests conservation are some of the largest and most cost-effective climate solutions available today. Conservation, sustainable management and restoration of forests can contribute to economic growth, poverty alleviation, rule of law, food security, climate resilience and biodiversity conservation [8].

The issue of enforcement of existing policy on charcoal export in Somalia is one that has persisted. With a government in its infancy, peace and stability continues to be the priority. It is hard to ignore the potential contribution to economic development that the charcoal trade has had on this community. Tackling this issue therefore requires speedy and multifaceted approach that deals with the complex reasons behind the trade. Poverty alleviation and alternative live- 
lihood sources are core issues that need to be addressed if any sustainable strategies for deforestation are to be implemented.

\section{Acknowledgements}

Jubaland administration for permission to conduct the survey.

\section{References}

[1] Girard, P. (2002) Charcoal Production and Use in Africa: What Future? Unasylva, 53, 30-35. http://www.fao.org/tempref/docrep/fao/005/y4450e/y4450e05.pdf

[2] Bailis, R., Ezzati, M. and Kammen, D.M. (2005) Mortality and Greenhouse Gas Impacts of Biomass and Petroleum Energy Futures in Africa. Science, 308, 98-103. https://doi.org/10.1126/science.1106881

[3] Brink, A.B., Eva, H.D. and Bodart, C. (2012) Is Africa Losing Its Natural Vegetation?-Monitoring Trajectories of Land-Cover Change Using Landsat Imagery. In: Giri, C.P., Ed., Remote Sensing of Land Use and Land Cover. Principles and Applications, CRC Press, Taylor \& Francis, Boca Raton, 369. https://doi.org/10.1201/b11964-28

[4] Zulu, L.C. and Richardson, R.B. (2013) Charcoal, Livelihoods, and Poverty Reduction: Evidence from Sub-Saharan Africa. Energy for Sustainable Development, 17, 127-137. https://doi.org/10.1016/j.esd.2012.07.007

[5] SWALIM (2014) Detection of Charcoal Production Sites on Southern Somalia Using Very High-Resolution Imagery.

[6] Sedano, F., Silva, J.A., Machoco, R., Meque, C., Sitoe, A., Ribeiro, N., Tucker, C., et al. (2016) The Impact of Charcoal Production on Forest Degradation: A Case Study in Tete, Mozambique. Environmental Research Letters, 11, Article ID: 094020. https://doi.org/10.1088/1748-9326/11/9/094020

[7] IPCC (2014) Africa. In: ClimateChange 2014: Impacts, Adaptation, and Vulnerability. Part B: Regional Aspects. Contribution of Working Group II to the Fifth Assessment Report of the Intergovernmental Panel on Climate Change, Cambridge University Press, Cambridge, and New York.

[8] UN-REDD (2015) UN-REDD Programme Strategic Framework 2016-20. http://www.unredd.net/index.php?view=download\&alias=14176-pb14-2016-2020-st rategic-framework-presentation\&category_slug=session-3-strategic-and-policy-issues\&o ption=com_docman\&Itemid=134

[9] Robinson, A. (1988) Charcoal-Making in Somalia: A Look at the Bay Method. An International Journal of the Forestry and Food Industries, 159. http://www.fao.org/docrep/s5780e/s5780e06.htm

[10] Little, P.D. (2004) Pastoralism in a Stateless Environment: The Case of the Southern Somalia Borderlands.

[11] IUCN (2006) Country Environmental Profile for Somalia.

[12] USAID (2014) Environmental and Natural Resource Management Assessment. https://usaid.gov/documents/1860/somalia-overview

[13] FGS (2012) Preparing Somalia's Future: Goals for 2015. http://somalikonferansi.mfa.gov.tr/about.en.mfa

[14] UNSC (2012) Resolution 2036. 
http://www.securitycouncilreport.org/atf/cf/\%7B65BFCF9B-6D27-4E9C-8CD3-CF6 E4FF96FF9\%7D/Somalia\%20S\%202012\%20176.pdf

[15] Rembold, F., Oduori, S.M., Gadainb, H. and Tose, P. (2013) Mapping Charcoal Driven Forest Degradation during the Main Period of Al Shabaab Control in Southern Somalia. Energy for Sustainable Development, 17, 510-514. https://doi.org/10.1016/j.esd.2013.07.001

[16] UNEP (2005) The State of the Environment in Somalia: A Desk Study. http://hdl.handle.net/20.500.11822/9792

[17] Beier, A.C. and Stephansson, E. (2012) Environmental and Climate Change Policy Brief Somalia. http://sidaenvironmenthelpdesk.se

[18] WB (2016) Data. The World Bank. http://data.worldbank.org/?locations=XL-SO

[19] UNEP \& INTERPOL (2014) The Environmental Crime Crisis: Threats to Sustainable Development from Illegal Exploitation and Trade in Wildlife and Forest Resources.

http://pfbc-cbfp.org/news_en/items/Environnmental-Crime-en.html?file=docs/new s/mai-juin14/Interpol-UNEP-RRAcrimecrisis.pdf

[20] Lettau, H., Lettau, K. and Molion, L.C.B. (1979) Amazonia's Hydrologic Cycle and the Role of Atmospheric Recycling in Assessing Deforestation Effects. Monthly Weather Review, 107, 227-238. https://doi.org/10.1175/1520-0493(1979)107<0227:AHCATR>2.0.CO;2

[21] D’Almeida, C., Vörösmarty, C., Hurtt, G., Marengo, J., Dingman, S.L. and Keim, B. (2007) The Effects of Deforestation on the Hydrological Cycle in Amazonia: A Review on Scale and Resolution. International Journal of Climatology, 27, 633-647. https://doi.org/10.1002/joc.1475

[22] Garcia-Carreras, L. and Parker, D.J. (2011) How Does Local Tropical Deforestation Affect Rainfall? Geophysical Research Letters, 38, L1980.

[23] Oduori, S.M., Rembold, F., Abdulle, O.H. and Vargas, R. (2011) Assessment of Charcoal Driven Deforestation Rates in a Fragile Rangeland Environment in North Eastern Somalia Using Very High Resolution Imagery. Journal of Arid Environments, 75, 1173-1181. https://doi.org/10.1016/j.jaridenv.2011.05.003

[24] FAO (2014) Detection of Charcoal Production Sites on Southern Somalia Using Very High-Resolution Imagery.

http://docplayer.net/63553806-Detection-of-charcoal-production-sites-on-southern -somalia-using-very-high-resolution-imagery-somalia.html

[25] Li, P., Jiang, L. and Feng, Z. (2014) Cross-Comparison of Vegetation Indices Derived from Landsat-7 Enhanced Thematic Mapper plus (ETM+) and Landsat-8 Operational Land Imager (OLI) Sensors. Remote Sensing, 6, 310-329. https://doi.org/10.3390/rs6010310

[26] Liang, S., Fang, H. and Chen, M. (2001) Atmospheric Correction of Landsat ETM+ Land Surface Imagery-Part I: Methods. IEEE Transactions on Geoscience and Remote Sensing, 39, 2490-2498. https://doi.org/10.1109/36.964986

[27] Chander, G., Markham, L.B. and Helde, L.D. (2009) Summary of Current Radiometric Calibration Coefficients for Landsat MSS, TM, ETM+, and EO-1 ALI Sensors. Remote Sensing of Environment, 113, 893-903. https://doi.org/10.1016/j.rse.2009.01.007

[28] Rawat, J.S. and Manish, K. (2015) Monitoring Land Use/Cover Change Using Remote Sensing and GIS Techniques: A Case Study of Hawalbagh Block, District Almora, Uttarakhand, India. The Egyptian Journal of Remote Sensing and Space Sci- 
ence, 18, 77-84. https://doi.org/10.1016/j.ejrs.2015.02.002

[29] Du, Y., Teillet, P. and Cihlar, J. (2002) Radiometric Normalization of Multitemporal High-Resolution Satellite Images with Quality Control for Land Cover Change Detection. Remote Sensing of Environment, 82, 123-134. https://doi.org/10.1016/S0034-4257(02)00029-9

[30] El Hajj, M., Bégué, A., Lafrance, B., Hagolle, O., Dedieu, G. and Rumeau, M. (2008) Relative Radiometric Normalization and Atmospheric Correction of a SPOT 5 Time Series. Sensors (BaseI), 8, 2774-2791. https://doi.org/10.3390/s8042774

[31] Mateos, C.J.B., Ruiz, C., Crespo, R. and Sanz, A. (2010) Relative Radiometric Normalization of Multitemporal Images. International Journal of Artificial Intelligence and Interactive Multimedia, 1, 54-59.

[32] Congalton, R.G. (2001) Accuracy Assessment and Validation of Remotely Sensed and Other Spatial Information. International Journal of Wildland Fire, 10, 321-328. https://doi.org/10.1071/WF01031

[33] Foody, G.M. (2002) Status of Land Cover Classification Accuracy Assessment. Remote Sensing of Environment, 80, 185-201. https://doi.org/10.1016/S0034-4257(01)00295-4

[34] Butt, A., Shabbir, R. and Ahmad, S.S. (2015) Land Use Change Mapping and Analysis Using Remote Sensing and GIS: A Case Study of Simply Watershed, Islamabad, Pakistan. The Egyptian Journal of Remote Sensing and Space Science, 18, 251-259. https://doi.org/10.1016/j.ejrs.2015.07.003

[35] Creative Research Systems (2016) Sample Size Calculator. http://www.surveysystem.com/sscalc.htm

[36] AMISOM (Producer) (2016) African Union Mission in Somalia Sector II Profile. http://amisom-au.org/wp-content/uploads/2013/11/Sector-II-Kismayo.pdf

[37] UNFPA (2014) Population Estimation Survey. United Nations Population Fund, Nairobi.

https://somalia.unfpa.org/sites/default/files/pub-pdf/Population-Estimation-Survey -of-Somalia-PESS-2013-2014.pdf

[38] Tremblay, M.-A. (2009) The Key Informant Technique: A Nonabto Graphic Application. American Anthropologist, 59, 688-701.

[39] Lambin, E.F., Turnerb, B.L., Agbolac, S.B., Angelsen, A., Brucee, J.W., Coomes, O.T., et al. (2001) The Causes of Land-Use and Land-Cover Change: Moving beyond the Myths. Global Environmental Change, 11, 261-269. https://doi.org/10.1016/S0959-3780(01)00007-3

[40] Gautam, A.P., Webb, E.L., Shivakoti, G. and Zoebisch, M. (2003) Land Use Dynamics and Landscape Change Patternin a Mountain Watershed in Nepal. Agriculture, Ecosystems and Environment, 99, 83-96. https://doi.org/10.1016/S0167-8809(03)00148-8

[41] Dewan, A.M. and Yamaguchi, Y. (2009) Using Remote Sensing and GIS to Detect and Monitor Land Use and Land Cover Change in Dhaka Metropolitan of Bangladesh during 1960-2005. Environmental Monitoring and Assessment, 150, 237-249.

[42] El-Kawy, O.R.A., Rød, J.K., Ismail, H.A. and Suliman, A.S. (2011) Land Use and Land Cover Change Detection in the Western Nile Delta of Egypt Using Remote Sensing Data. Applied Geography, 31, 483-494. https://doi.org/10.1016/j.apgeog.2010.10.012

[43] EM-DAT (2016) The International Disaster Database. The International Disaster Database. http://www.emdat.be 
[44] Ogallo, L.A., Ouma, G. and Omondi, P. (2017) Changes in Past and Present Rainfall and Surface Temperature over Lower Jubba, Somalia. Journal of Climate Change and Sustainability, 1, 39-52.

[45] Cagnolati, V., Tempia, S. and Abdi, A.M. (2006) Economic Impact of Rift Valley Fever on the Somali Livestock Industry and a Novel Surveillance Approach in Nomadic Pastoral Systems. 11th International Symposium on Veterinary Epidemiology and Economics, Cairns.

[46] Vieira, D.L.M. and Scariot, A. (2006) Principles of Natural Regeneration of Tropical Dry Forests for Restoration. Restoration Ecology, 14, 11-20. https://doi.org/10.1111/j.1526-100X.2006.00100.x

[47] Zhang, S., Kang, H. and Yang, W. (2017) Climate Change-Induced Water Stress Suppresses the Regeneration of the Critically Endangered Forest Tree Nyssa yunnanensis. PLoS ONE, 12, e0182012.

[48] Huang, C.Y. and Anderegg, W.R. (2012) Large Drought-Induced Aboveground Live Biomass Losses in Southern Rocky Mountain Aspen Forests. Global Change Biology, 18, 1016-1027.

[49] Enwezor, F.N.C. and Sackey, A.K.B. (2005) Camel Trypanosomosis-A Review. Veterinarinarki Arhiv, 75, 439-452. https://hrcak.srce.hr/file/50720

[50] Geist, H.J. and Lambin, E.F. (2002) Proximate Causes and Underlying Driving Forces of Tropical Deforestation. BioScience, 52, 143-150. https://doi.org/10.1641/0006-3568(2002)052[0143:PCAUDF]2.0.CO;2

[51] Bachorz, B. (2012) Massive Deforestation Risks Turning Somalia into Desert. https://www.capitalfm.co.ke/news/2012/11/massive-deforestation-risks-turning-so malia-into-desert/

[52] MoPD\&E (2004) Impact of Charcoal Production on Environment and the Socio Economy of Pastoral Communities of Somaliland.

http://www.candlelightsomal.org/wp-content/uploads/2014/07/Case-study-Charcoa 1-production-in-Somaliland.pdf

[53] Paavola, J. (2008) Livelihoods, Vulnerability and Adaptation to Climate Change in Morogoro, Tanzania. Environmental Science \& Policy, 11, 642-654.

[54] Melaku, B. and Zenebe, G. (2014) Reading through the Charcoal Industry in Ethiopia: Production, Marketing, Consumption and Impact. Forum for Social Studies (FFS), Addis Ababa.

[55] Smith, H.E., Hudson, M.D. and Schreckenberg, K. (2017) Livelihood Diversification: The Role of Charcoal Production in Southern Malawi. Energy for Sustainable Development, 36, 22-36.

[56] Jones, D., Ryan, C. and Fisher, J. (2016) Charcoal as a Diversification Strategy: The Flexible Role of Charcoal Production in the Livelihoods of Smallholders in Central Mozambique. Energy for Sustainable Development, 32, 14-21. https://doi.org/10.1016/j.esd.2016.02.009

[57] FGS (2015) Somalia Energy Sector Needs Assessment and Investment Programme. https://www.afdb.org/fileadmin/uploads/afdb/Documents/Generic-Documents/Fin al_Somalia_Energy_Sector_Needs_Assessment_FGS_AfDB_November_2015.pdf

[58] Hosonuma, N., Herold, M., De Sy, V., De Fries, R.S., Brockhaus, M., Verchot, L., Romijn, E., et al. (2012) An Assessment of Deforestation and Forest Degradation Drivers in Developing Countries. Environmental Research Letters, 7, Article ID: 044009. https://doi.org/10.1088/1748-9326/7/4/044009 